\title{
Permeability of High-Performance Fiber Reinforced Concrete Immersed in High Concentration Sodium Chloride Solution
}

\author{
Lyes Chalah ${ }^{1 *}$, Aissa Talah \\ 1 Department of Structures and Materials, Built Environmental Research laboratory, University of Sciences and Technology \\ Houari Boumediene (USTHB), BP 32 El Alia, Bab Ezzouar, Algiers, Algeria \\ * Corresponding author, e-mail: lychalah@usthb.dz
}

Received: 03 December 2021, Accepted: 13 February 2022, Published online: 18 February 2022

\begin{abstract}
This paper aims to study the permeability of High-Performance Concrete containing natural pozzolan and reinforced with fibers in high concentration sodium chloride solution. Optimized finely ground natural pozzolan was employed as $6 \%$ of partial substitution of the cement. Polypropylene fibers with $6 \mathrm{~mm}$ and $12 \mathrm{~mm}$ lengths were introduced individually for a volume fraction of $0.1 \%$ and $0.15 \%$ respectively. Then, in combination with a total fiber content of $0.25 \%$. The effect of sodium chloride attack on the performance of concretes was assessed through the measurement of the compressive strength, splitting tensile strength, sorptivity, rapid chloride permeability test, apparent and intrinsic gas permeability, and visual inspection at various testing ages (28, 90, 180, and 365 days). A total of four (04) types of concretes were cast: one (01) High-Performance Concrete (HPC), and three (03) High-Performance Fiber Reinforced Concrete (HPFRC) stored in tap water and sodium chloride environment. From the experiments performed, it can be concluded that the polypropylene fibers introduction into HPC favorably affect its chemical resistance to chloride attack and longterm durability. The difference in the permeability of HPC and HPFRC stored in tap water and chloride environment is not significant. Furthermore, the visual investigation of HPFRC after 365 days of immersion in sodium chloride environment showed no sign of degradation. Based on the results obtained in this study, we recommend the use of hybrid fiber-reinforced concrete (F0-0.25\%) as a low permeable material in a severe chloride environment.
\end{abstract}

Keywords

natural pozzolan, fiber reinforced concrete, durability, permeability, chloride attack

\section{Introduction}

High-Performance Concrete (HPC) is a high technology and engineering material, combining high strength, low porosity, and minimum permeability to the penetration of external aggressive agents. The fulfillment of these criteria usually requires the adequate use of superplasticizer and mineral additions like fly ash, silica fume, blast furnace slag and natural pozzolan [1]. Mineral additions of natural or artificial origin are generally used alongside HPCs as a replacement of part of the cement for economic and ecological purposes [2]. Mineral addition, also participates in the improvement of the fresh and hardened state of concretes [3]. The gains obtained are often accompanied by a reduction of the pollution of the atmosphere [4], and improved mechanical strengths and long-term durability of HPCs [5].

Several scholars have observed these improvements through the use of Algerian natural pozzolan [6]. Senhadji et al. [7] highlighted the positive influence of natural pozzolan, as a partial substitution for cement in decreasing peak temperature and the cooling slope, particularly in large masses of concrete (e.g., dams), which results in a flattening of the thermal gradient and a reduction of the risk of cracking in massive concrete structures. At early ages, the strengths of concretes incorporating pozzolan are below than that of plain concretes. However, the strengths gap decreases gradually over time and can reach at least the same magnitude of strength after longer curing periods [8]. Also, the natural pozzolan significantly contributes to the durability of concrete. This mineral addition can favorably affect the resistances of cementitious material that enters in interaction with harmful substances such as hydrochloric and sulphuric acid as well as sulfates media [9]. Despite these additions, this type of concrete retains its main weakness, which is a reduced capacity in tension [10], thus limiting its use and negatively 
influencing its safety and durability [11]. Another major weakness of concrete structures is the appearance of cracks even before the concrete has hardened [12]. The improvement of the tensile strength and the restriction of crack development can be achieved by the incorporation of discrete fibers [13]. Fibers act through bridging action between cracks, by absorbing the tensile stresses and by providing improved resistance to shear through the surfaces of cracks [14]. Thus, the concerned material shows better ductility, energy absorption, and dissipation capacity [15]. Also, due to their hydrophobicity and appropriate chemical resistance, polypropylene fibers can demonstrate long-term durability in a deleterious environment [16].

Concrete construction in contact with seawater can be severely damaged with time. The presence of deleterious substances in the form of chloride ions, sulfate ions, and magnesium ions is the source of the aggressiveness of this medium. The majority of these substances can, once in contact with the cement products, react chemically and form new components. The resulting products can be the source of important disorders and loss of resistance and durability of the affected structures [17]. On the other hand, when water and oxygen are available, and the presence of chlorides at the interface of the reinforcement exceeds the threshold value, the corrosion process can start. The corrosion process of steel reinforcements leads to cracking and spalling of concrete cover. Therefore, corrosion of reinforced concrete is considered as the leading cause of concrete durability [18].

The reaction of sodium chlorides $\mathrm{NaCl}$ in the presence of calcium hydroxide $\mathrm{Ca}(\mathrm{OH})_{2}$ and with tricalcium aluminate $\mathrm{C}_{3} \mathrm{~A}$ generates the formation of a new product named Friedel's salt $\mathrm{C}_{3} \mathrm{~A} \cdot \mathrm{CaCl}_{2} \cdot 10 \mathrm{H}_{2} \mathrm{O}$. The formation of this new salt represents the principal threat to the cementitious materials in contact with $\mathrm{NaCl}$ solution. As reported by Peterson [19], sodium chloride solutions have a negligible influence on the mechanical properties of cementitious material. In another study, Darwin et al. [20] observed, that at lower sodium chloride concentration (3\%), the solution has no important effect on the properties of concretes.

Permeability is the key attribute for assessing the longterm durability of concrete structures [21]. Permeability as a transfer parameter defines the ability of an external liquid, gas, or other deleterious substances to move through a porous material under a pressure difference. High permeability accelerates the movement of fluids and their penetration through the concrete, which reduces their service life. While, low permeability delays fluid penetration as well as concrete degradation [22]. Permeability is intimately linked to two main factors [23]. The first factor is represented by the pore structure and the connection of the pore network. The second factor is represented by the micro-cracks formed in the concrete. The pore structure and the number of connected pores depend on both the water to cement ratio, the progress of the hydration reaction, and the degree of consolidation. On the other hand, the appearance of micro-cracks is controlled by the level of applied stresses or deformation, internal or external, that the concrete undergoes during its lifetime. The applied deformation or stresses are the consequence of shrinkage, thermal gradient, volumetric instability, or imposed dead and live loads [23].

Previous researches showed the beneficial addition of fibers in enhancing the mechanical properties of concretes. Also, several existing papers are discussing the performance of polypropylene fiber-reinforced concrete under chloride attack in low concentration. However, a limited number of studies report the behavior of Fiber Reinforced Concrete (FRC) in a high concentration of sodium chloride environment. Therefore, the main purpose of this experimental research was to study the feasibility of developing impermeable High-Performance Fiber Reinforced Concrete (HPFRC) in 10\% concentration of Sodium Chloride $(\mathrm{NaCl})$ solution. In this regard, an experimental campaign was carried out to assess the permeability of HPC mixtures incorporating $6 \%$ of natural pozzolan and reinforced with two types of polypropylenes fibers $(6 \mathrm{~mm}$ and $12 \mathrm{~mm}$ of long) individually and in hybridization. The compressive strength, splitting-tensile strength, sorptivity, Rapid Chloride Permeability Test (RCPT), apparent and intrinsic gas permeability are measured at various curing times (28, 90, 180, and 365 days). A visual investigation is also performed and discussed in this research paper.

\section{Experimental program}

\subsection{Materials}

In this study, Ordinary Portland Cement (OPC) CEM I with strength class 42.5 was used in the fabrication of all concretes. Local Natural Pozzolan (NP) extracted from the Beni-Saf deposit, located in North-West Algeria (see Fig. 1(a)) was finely ground into a powder (see Fig. 1(b)) then used as a $6 \%$ replacement of cement weight. The chemical compositions and physical characteristics of cement and pozzolan are given in Table 1. Fine aggregate, consisting of natural rolled river sand with a maximum size of $5 \mathrm{~mm}$ and a median diameter of $2 \mathrm{~mm}$ was employed. 


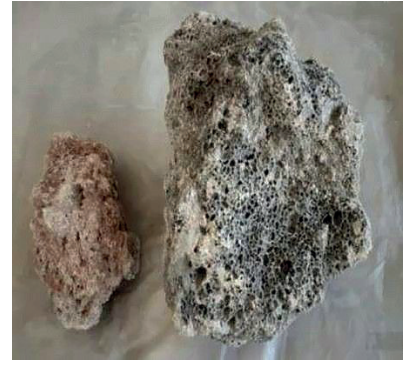

(a)

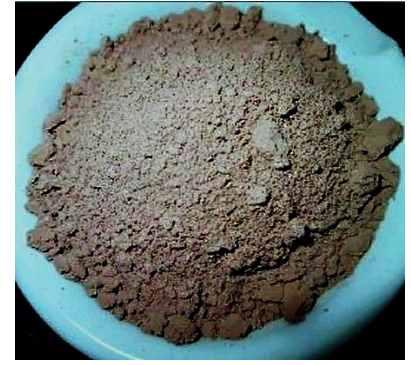

(b)
Fig. 1 View of the natural pozzolan (a) at natural state and (b) after grinding

Two classes of coarse aggregate with a maximum size of $8 \mathrm{~mm}$ and $16 \mathrm{~mm}$ were utilized. The physical properties of aggregates are shown in Table 2. Polypropylene fibers with $6 \mathrm{~mm}$ and $12 \mathrm{~mm}$ in length were introduced individually into concretes at a volume fraction of $0.1 \%$ and $0.15 \%$, respectively, and in combination at a total volume fraction of $0.25 \%$. The mechanical properties and visual aspects of each fiber are indicated in Table 3 and Fig. 2, respectively. To reduce the side effect of fibers introduction on the workability of concretes, a commercially available High-Range Water-Reducer admixture, Tempo 12, based on a copolymer acrylic, with a specific gravity of 1.06 was employed in all concretes.

\subsection{Concrete mixture proportioning}

To achieve the objectives of this experimental study, four (04) concretes were produced using the Dreux-Goriss method. One concrete (01) without fibers and three (03) concretes containing $0.1 \%, 0.15 \%$, and $0.25 \%$ of polypropylene fibers of length $6 \mathrm{~mm}, 12 \mathrm{~mm}$ and their combinations, respectively. All the compositions realized in this study, have a constant water/binder ratio of 0.3 and $6 \%$ of natural pozzolan as partial substitution of cement. Table 4 presents the proportions of concretes mixtures and their workability.

\subsection{Specimens preparation and curing}

A power-driven revolving pan mixer with a capacity of $90 \mathrm{~L}$ was used in the production of all compositions. For this purpose, the fine and coarse aggregates were introduced and mixed for $2 \mathrm{~min}$. Then, cement and natural pozzolan are gradually introduced to aggregate and mixed
Table 2 The physical properties of aggregates

\begin{tabular}{lccc}
\hline Property & Sand 0/5 & Gravel 3/8 & Gravel 8/16 \\
\hline Specific gravity & 2.6 & 2.7 & 2.7 \\
Fineness modulus & 3.2 & - & - \\
Equivalent of sand (\%) & 95 & - & - \\
Water absorption (\%) & 1.1 & 0.1 & 0.1 \\
Los Angeles (\%) & - & 33 & 30 \\
Flattening Coefficient (\%) & - & 28 & 25 \\
Micro-Deval test (\%) & - & 24 & 20 \\
\hline
\end{tabular}

Table 3 Properties of polypropylene fibers used

\begin{tabular}{lcccccc}
\hline $\begin{array}{l}\text { Fiber } \\
\text { type }\end{array}$ & $\begin{array}{c}\text { Fiber } \\
\text { shape }\end{array}$ & $\begin{array}{c}\text { Length } \\
1(\mathrm{~mm})\end{array}$ & $\begin{array}{c}\text { Diameter } \\
\mathrm{d}(\mathrm{mm})\end{array}$ & $\begin{array}{c}\text { Aspect } \\
\text { ratio 1/d }\end{array}$ & $\begin{array}{c}\text { Tensile } \\
\text { strength } \\
(\mathrm{MPa})\end{array}$ & $\begin{array}{c}\text { Specific } \\
\text { gravity }\end{array}$ \\
\hline PPF6 & Straight & 6 & 0.034 & 176 & 350 & 0.91 \\
PPF12 & Straight & 12 & 0.034 & 353 & 350 & 0.91 \\
\hline
\end{tabular}

PPF6: Polypropylene fiber of $6 \mathrm{~mm}$ long; PPF12: Polypropylene fiber of $12 \mathrm{~mm}$ long

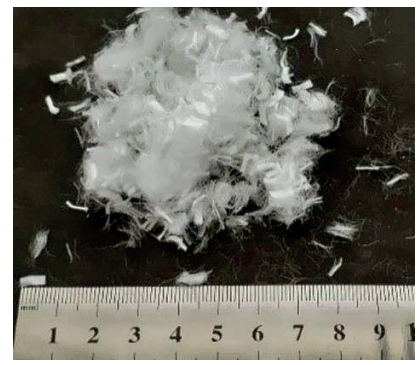

(a)

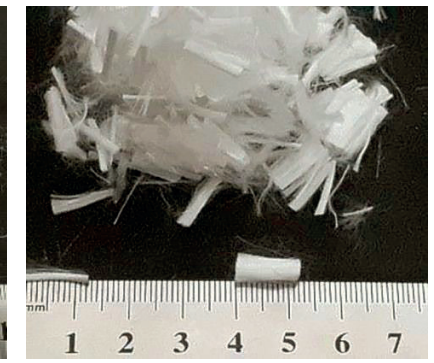

(b)
Fig. 2 Polypropylene fibers employed in this study: (a) PPF6 and (b) PPF12

again for $2 \mathrm{~min}$. Half of the superplasticizer and the mixing water are progressively added to the dry mix and left for 2 minutes. Afterward, the remaining amount of superplasticizer and water was added to the concrete and mixed for 2 minutes.

Finally, the polypropylene fibers were gradually introduced and the mixing process continued until a uniform concrete was obtained. After the completion of the mixing process, the workability of the fresh concrete was determined using the slump cone. Then, cast into various molds of different dimensions (see Fig. 3(a) and Fig. 3(b)), depending on the test, and compacted using a vibrating table. The molded specimens were covered with a plastic sheet, in order to prevent water evaporation. After $24 \mathrm{~h}$,

Table 1 Chemical compositions of cement and natural pozzolan in (\%)

\begin{tabular}{|c|c|c|c|c|c|c|c|c|c|}
\hline Component (\%) & $\mathrm{CaO}$ & $\mathrm{SiO}_{2}$ & $\mathrm{Al}_{2} \mathrm{O}_{3}$ & $\mathrm{Fe}_{2} \mathrm{O}_{3}$ & $\mathrm{~K}_{2} \mathrm{O}$ & $\mathrm{Na}_{2} \mathrm{O}$ & $\mathrm{MgO}$ & $\mathrm{SO}_{3}$ & LOI \\
\hline Cement & 62.98 & 21.05 & 3.99 & 5.09 & 0.59 & 0.18 & 1.30 & 2.42 & 1.81 \\
\hline Natural Pozzolan & 9.47 & 43.87 & 16.63 & 10.68 & 1.23 & 1.37 & 4.46 & 0.23 & 8.93 \\
\hline
\end{tabular}


Table 4 Proportions of concrete mixtures

\begin{tabular}{|c|c|c|c|c|c|c|c|c|c|c|}
\hline Mixture description & $\mathrm{W} / \mathrm{B}$ & Water & $\begin{array}{r}\text { Cement } \\
(\mathrm{k}\end{array}$ & $\begin{array}{l}\text { Pozzolan } \\
\left./ \mathrm{m}^{3}\right)\end{array}$ & Sand $0 / 5$ & Gravel 3/8 & Gravel 8/16 & $\mathrm{SP} *(\%)$ & Fiber content $(\%)$ & Slump (cm) \\
\hline $\mathrm{F} 0^{*}$ & 0.3 & 120 & 376 & 24 & 718 & 145 & 927 & 1.25 & 0 & 23.0 \\
\hline F0.10* & 0.3 & 120 & 376 & 24 & 718 & 145 & 927 & 1.25 & 0.1 & 17.5 \\
\hline F0.15* & 0.3 & 120 & 376 & 24 & 718 & 145 & 927 & 1.25 & 0.15 & 19.0 \\
\hline F $0.25^{*}$ & 0.3 & 120 & 376 & 24 & 718 & 145 & 927 & 1.25 & 0.25 & 12.0 \\
\hline
\end{tabular}

*F0: High Performance Concrete without fibers; F0.10: High Performance Fiber Reinforced Concrete with 0.1\% of PPF6; F0.15: High Performance Fiber Reinforced Concrete with $0.15 \%$ of PPF12; F0.25: High Performance Fiber Reinforced Concrete with $0.1 \%$ of PPF6 and $0.15 \%$ of PPF 12

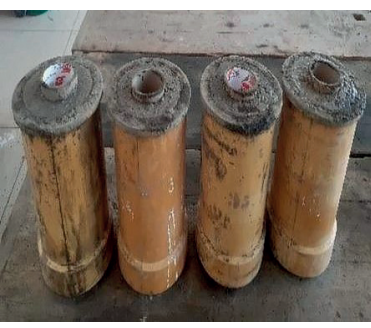

(a)

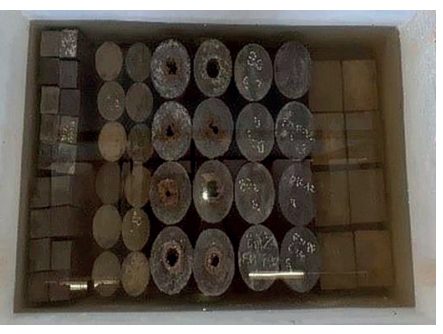

(b)
Fig. 3 (a) Casting and (b) conservation of concretes

the specimens were demolded and stored in two conservation environments: (1) standard curing in Tap Water (TW) as a reference standard curing. (2) Sodium Chloride Water (SCW) at $10 \%$ concentration was used to evaluate the effect of aggressive chloride environments such as those encountered by structures subjected to the marine environment and those used as deicing salt in concrete pavement. Table 5 describes the notation employed in this study.

\subsection{Testing procedure}

\subsubsection{Mechanical strengths}

Compressive strength tests were conducted on $(150 \times 150$ $\times 150) \mathrm{mm}$ cubic specimens using a $2000 \mathrm{kN}$ universal compression machine following ASTM C39 [24]. Splitting tensile strength tests were evaluated on $(160 \times 320) \mathrm{mm}$ cylinder specimens according to the specifications of ASTM C496 [25]. The mechanical strengths experiment was measured on three (03) specimens at various times $(28,90,180$, and 365 days).

\subsubsection{Sorptivity}

Capillary absorption represents an interesting parameter for the estimation of durability of concretes, as it assesses the transport of deleterious substances (chloride and sulphates) into the pores network [26]. The rate of water absorption, also known as sorptivity was performed in accordance with the ASTM C1585 [27] on three (03) samples at different time (28, 90, 180 and 365 days). After the adequate time of wet conservation, the specimens sawn were introduced in

\begin{tabular}{|c|c|}
\hline Notation & Concretes and cured environment \\
\hline F0-TW & High Performance Concrete stored in tap water \\
\hline F0-SCW & $\begin{array}{l}\text { High Performance Concrete stored in sodium chloride } \\
\text { water }\end{array}$ \\
\hline F0.1-TW & $\begin{array}{l}\text { High Performance Fiber Reinforced Concrete stored } \\
\text { in tap water }\end{array}$ \\
\hline F0.1-SCW & $\begin{array}{l}\text { High Performance Fiber Reinforced Concrete stored } \\
\text { in sodium chloride water }\end{array}$ \\
\hline F0.15-TW & $\begin{array}{l}\text { High Performance Fiber Reinforced Concrete stored } \\
\text { in tap water }\end{array}$ \\
\hline F0.15-SCW & $\begin{array}{l}\text { High Performance Fiber Reinforced Concrete stored } \\
\text { in sodium chloride water }\end{array}$ \\
\hline F0.25-TW & $\begin{array}{l}\text { High Performance Fiber Reinforced Concrete stored } \\
\text { in tap water }\end{array}$ \\
\hline F0.25-SCW & $\begin{array}{l}\text { High Performance Fiber Reinforced Concrete stored } \\
\text { in sodium chloride water }\end{array}$ \\
\hline
\end{tabular}

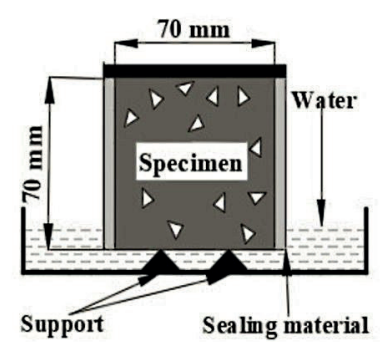

(a)

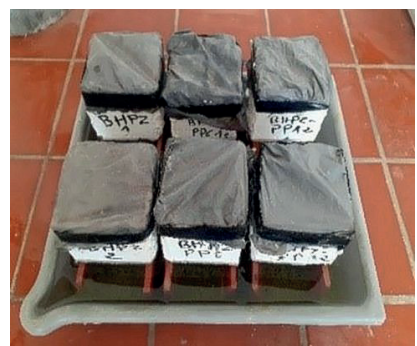

(b)
Fig. 4 (a) Schematic representation and (b) general view of the sorptivity test

an oven dry at a temperature of $50^{\circ} \mathrm{C}$ for 3 days. The sorptivity measurement was obtained testing specimens $(70 \times 70 \times 70) \mathrm{mm}$, sawn from $(70 \times 70 \times 280) \mathrm{mm}$ prismatic specimens. The bottom surface of the specimen sawn was exposed to water at a depth of $5 \mathrm{~mm}$ while the top surface was covered with a plastic sheet and the borders coated with a sealing material (see Fig. 4). The change in the mass is measured between the periods of $1 \mathrm{mn}$ to $6 \mathrm{~h}$ and the sorptivity values are calculated with the following formula:

$S=A / t^{0.5}$ 
where $S$ represents the sorptivity $\left(\mathrm{cm} / \mathrm{mn}^{2}\right)$; $I$ is the absorption $(\mathrm{cm})$ obtained from the change in mass divided by the product of the cross-sectional area of the test specimen and the density of water; $t$ is the square root of time $\left(\mathrm{mn}^{0.5}\right)$.

\subsubsection{Rapid Chloride Permeability Test (RCPT)}

The rapid chloride permeability test shown in Fig. 5 is an electrical test performed according to the specifications of ASTM C1202 [28] on three concretes specimen (03) at various testing times (from 28 to 365 days). The specimens used for this test was a $(110 \times 50) \mathrm{mm}$, sawn from cylinder specimens $(110 \times 220) \mathrm{mm}($ see Fig. 5). After specified curing periods, the borders were coated with sealing material. Then, placed between two (02) cells, one cell filled with $3 \% \mathrm{NaCl}(-)$ and the other cell filled with $0.3 \mathrm{~N} \mathrm{NaOH}(+)$. The cells were connected to a $60 \mathrm{~V}$ electrical current and a multimeter for 6 hours. At the end, the total charge passed in Coulombs through concretes is calculated by the following formula (Eq. (2)):

$Q=900\left(I_{0}+2 I_{30}+\ldots+2 I_{330}+I_{360}\right)$,

where $Q$ represents the total charge passed (Coulombs), $I_{0}$ is the current (amperes) immediately after voltage is applied and $I_{t}$ is the current (amperes) at $t$ minute after voltage is applied.

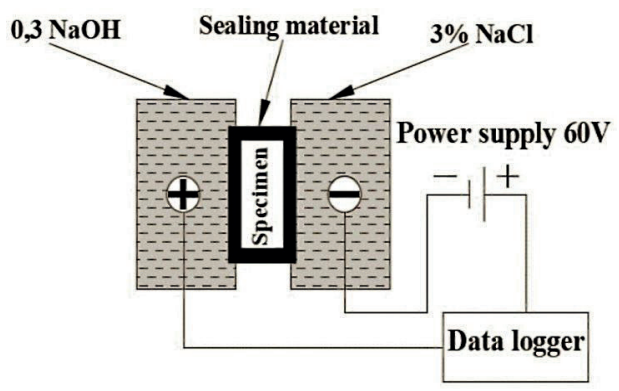

(a)

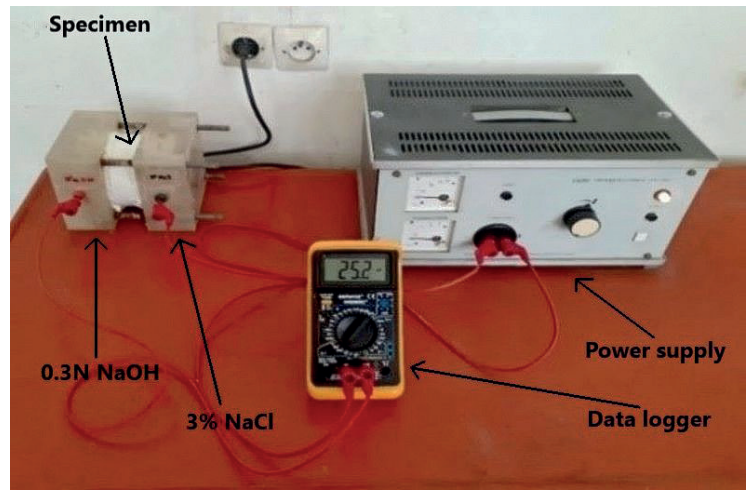

(b)

Fig. 5 (a) Schematic representation and (b) general view of the experimental set up of Rapid Chloride Permeability Test

\subsubsection{Apparent and intrinsic gas permeability}

The gas permeability of each formulated specimen is evaluated using the modified test procedure proposed by Talah and Kharchi [29].

The proposed setup differs from the other setups by the cell, which is the main element of the experimental procedure as well as by the elimination of the confining pressure and the air cylinder. The originality of this experiment lies in the shape of the sample, which is a hollow cylinder that reflects real construction cases [29]. Subsequently, hollow cylindrical specimens with dimensions $(160 \times 100) \mathrm{mm}$ were used for gas permeability measurements. The holes were made with an $80 \mathrm{~mm}$ diameter paper pipe to obtain an accurate thickness of $40 \mathrm{~mm}$ to be penetrated by the gas (see Fig. 6). The specimens were introduced into an oven at $80{ }^{\circ} \mathrm{C}$ for 28 days and then subjected to $105{ }^{\circ} \mathrm{C}$ until a constant weight was achieved as recommended by AFPC-AFREM [30]. After that, the specimens were protected laterally and held vertically, ensuring a unidirectional radial flow of gas. The apparent gas permeability is determined by the measurement of gas flow percolation through concrete samples and calculated using the following formula (Eq. (3)):

$K_{a}=\frac{2 \times Q \times P_{a t m} \times\left(R_{2}^{2}-R_{1}^{2}\right) \times \mu}{\left(P^{2}-P_{a t m}{ }^{2}\right) \times \pi \times h \times\left(R_{2}+R_{1}\right)}$,

where $h$ is the specimens thickness (m), $Q$ is the gas debit $\left(\mathrm{m}^{3} / \mathrm{s}\right), P$ and $P_{\text {atm }}$ are the inlet and outlet (atmospheric) pressure respectively $\left(\mathrm{N} / \mathrm{m}^{2}\right), R_{2}$ and $R_{1}$ are the inner and outer radius, respectively, of the concrete specimen (m), $\mu$ is the gas dynamic viscosity $\left(\mathrm{Ns} / \mathrm{m}^{2}\right)$, for the oxygen which was the gas used in this test $\mu=20.2 \times 10^{-16} \mathrm{Ns} / \mathrm{m}^{2}$ at $20^{\circ} \mathrm{C}$.

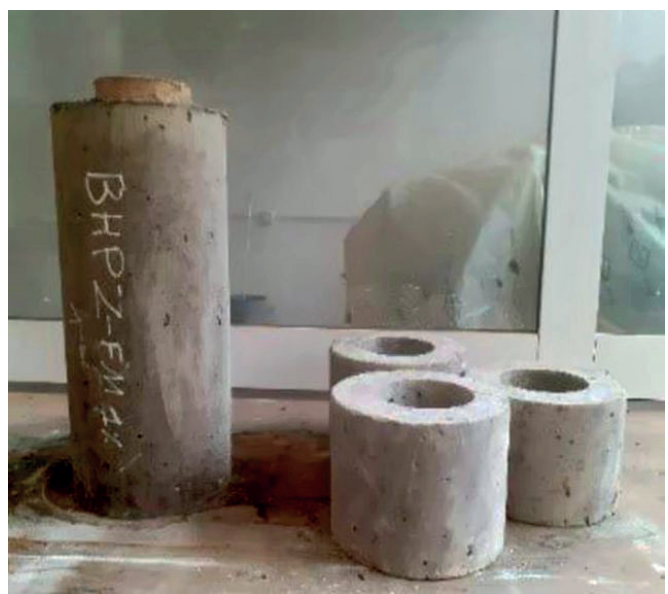

Fig. 6 View of the hollow cylinder concretes 


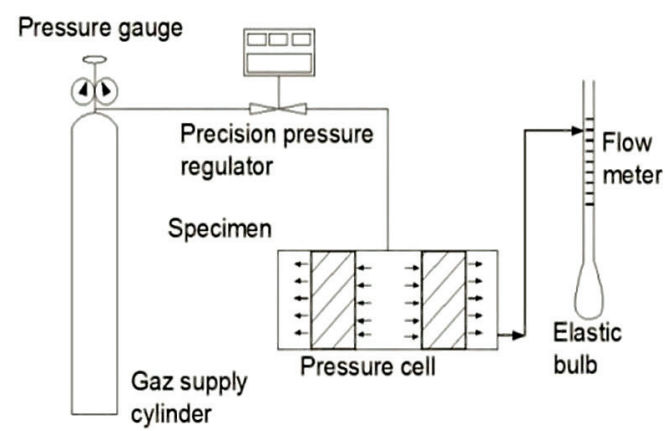

(a)

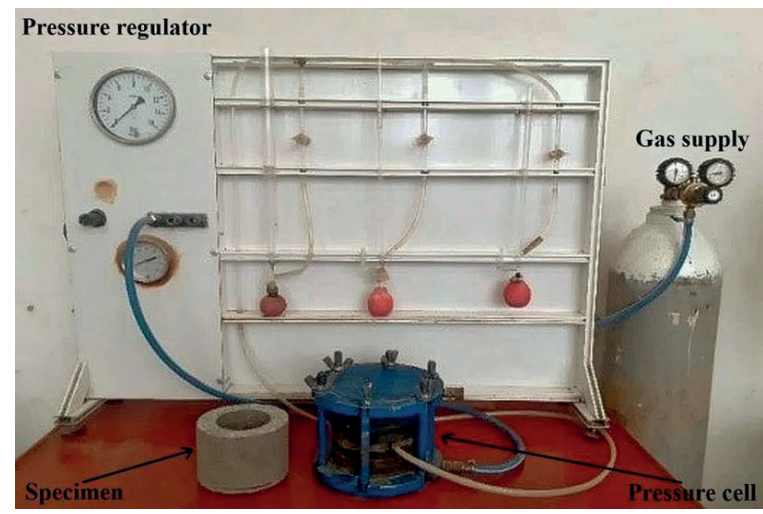

(b)

Fig. 7 (a) Schematic layout and (b) visual aspect of gas permeability apparatus used in this study [23]

It is worth noting, that the oxygen permeability was measured at a constant pressure of $0.2 \mathrm{MPa}$ for all concrete mixtures and required a period of $6 \mathrm{~h}$ to achieve a single measurement in some compositions. The general view of the test apparatus used is shown in Fig. 7.

In order to characterize the concrete porous network alone, the intrinsic oxygen permeability $\left(K_{\text {in }}\right)$ was determined through the Klinkenberg's correlation [31]. The intrinsic oxygen permeability is independent of the gas pressure and corresponds only to the viscous flow of the percolating fluid [32], This method consists of measuring at least three apparent oxygen permeability values $(0.2,0.3$ and $0.4 \mathrm{MPa}$ were chosen in this study) and plotting it against the inverse mean pressure $\left(1 / P_{m}\right)$. The intrinsic permeability $\left(K_{i n}\right)$ represents the value of the apparent permeability where the mean pressure $\left(P_{m}\right)$ tends towards infinity, that is to say when the gas tends towards a condensed (liquid) phase [33]. The Klinkenberg's method is given by the following equation:

$$
\begin{gathered}
K_{a}=K_{a}\left(\frac{\beta}{P_{m}}\right), \\
P_{m}=\frac{P_{a t m}+P}{2},
\end{gathered}
$$

where $K_{a}\left(\mathrm{~m}^{2}\right)$ is the apparent permeability, $K_{\text {int }}\left(\mathrm{m}^{2}\right)$ is the intrinsic permeability, $\beta(\mathrm{Pa})$ is the Klinkenberg's constant, $P_{m}\left(\mathrm{~m}^{2}\right)$ is the mean pressure.

The gas permeability measurements of concrete were performed at 28, 90,180 and 365 days of age. The results reported are the average of three (03) specimens.

\section{Results and discussion}

\subsection{Mechanical strengths}

The experimental results on strengths of the fiber-reinforced concrete and the plain concretes cured at 28, 90, 180 , and 365 days in tap water and chloride solution are presented in Fig. 8 and Fig. 9. The introduction of polypropylenes fibers into High-Performance Concretes influence differently the strengths result. The incorporation of polypropylenes fibers and their combination resulted in a loss of compressive strength when compared with the unreinforced HPC mixtures, regardless of curing age and water conservations. On the opposite, the splitting-tensile strength was improved with the introduction of fibers at the same volumetric dosage and testing time. For example, the introduction of $0.1 \%, 0.15 \%$, and $0.25 \%$ of polypropylenes fibers into HPC immersed in two surrounding waters reduced the compressive strength by $10 \%, 12 \%$, and

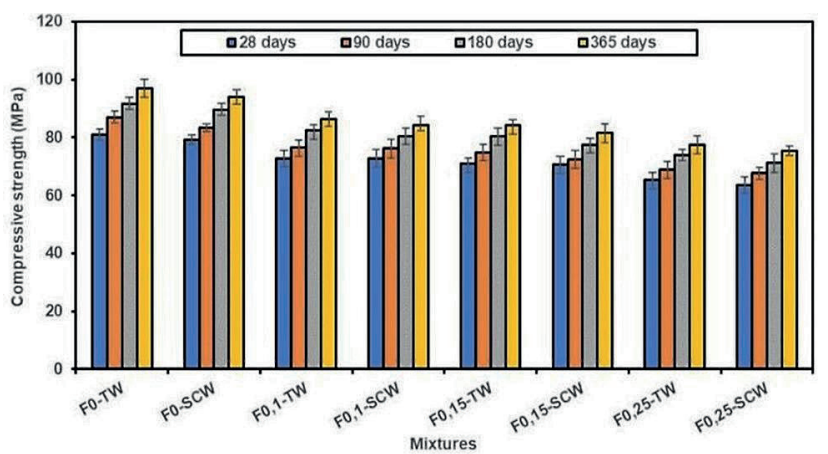

Fig. 8 Compressive strength of all specimens stored in two conservation environments at 28,90, 180 and 365 days

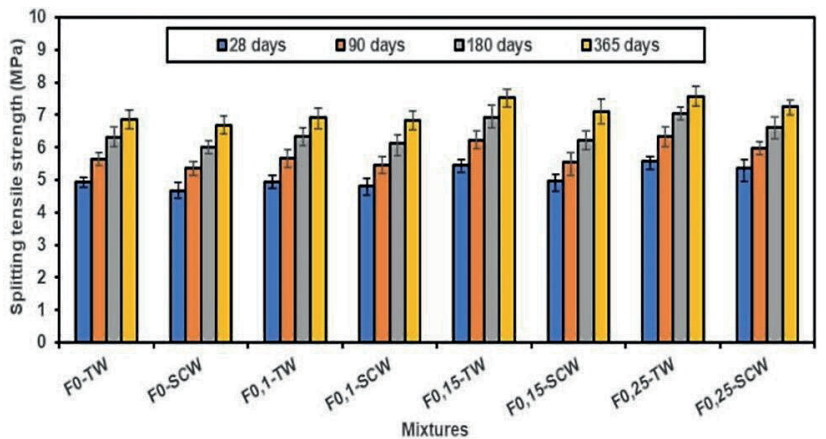

Fig. 9 Splitting-tensile strength of all specimens stored in two conservation environments at 28,90, 180 and 365 days 
$20 \%$, respectively, compared with the unreinforced HPC at 28 days. This reduction in the compressive strength is due to the growth of porosity and the rate of trapped air in the concrete [34]. Tabatabaeian et al. [35] observed a similar decrease with the replacement of steel fibers by polypropylenes fibers with a loss of up to $38 \%$ compared to the control sample. On the other hand, the splitting-tensile strength increased by $4 \%, 11 \%$, and $15 \%$ for the concrete specimens stored in tap and chloride water and containing $0.1 \%, 0.15 \%$, and $0.25 \%$ of polypropylene fiber, respectively, compared with the plain concrete at 28 days. The results are in agreement with the finding of Zhang and Zhao [36], that reported an increase in the splitting-tensile strength by $41.5 \%, 43.9 \%, 85.4 \%$, and $87.8 \%$ for the concrete specimens containing $0.6,0.9,1.2$, and $1.5 \mathrm{~kg} / \mathrm{m}^{3}$ polypropylene fiber, respectively, compared with the plain concrete at 28 days. This improvement is related to the ability of polypropylene fibers to bridge the split portions of the matrix by acting through the stress transfer from the matrix to the fibers once the splitting stress happened and continued. Thus, the polypropylene fibers gradually carried the total load, improved the tensile strain capacity of concretes, and consequently, the splitting-tensile strength of the fiber-reinforced concretes in comparison with unreinforced concretes [37].

From Figs. 8 and 9, it can be observed that after a test duration ranging from 28 to 365 days, the difference in strengths variation of the HPC and HPFRC specimens stored in drinking water and those conserved in $10 \%$ concentration of sodium chloride is negligible. This difference was less than $4 \%$ for the compressive strength and $11 \%$ for the splitting-tensile strength. The minimum difference in the strengths of HPC and HPFRC stored in the two-water conservation that polypropylene fibers had a negligible incidence on the properties of concrete. Thus, high-performance concretes incorporating polypropylene fibers were not damaged by the chloride attack. In addition, the continuous rate of hydration and replacement of cement with $6 \%$ of fine natural pozzolan reduced the global porosity, as well as the quantity of available Calcium Hydroxide $\left(\mathrm{Ca}(\mathrm{OH})_{2}\right)$. This addition further participated in preventing the degradation of concretes.

It is noteworthy that the HPCs incorporating polypropylenes fiber of $6 \mathrm{~mm}$ and $12 \mathrm{~mm}$ length obtained very comparable strengths values after exposure to $10 \%$ concentration of sodium chloride for $28,90,180$, and 365 days. It implies that fiber length does not participate in the degradation of the concrete immersed in a chloride environment.

\subsection{Sorptivity}

Sorptivity of concretes describes the ability of external water to move through the pores network by the mean of capillary suction [3]. Fig. 10 shows the average values of the results obtained for the sorptivity of all concrete conserved in tap water and $10 \%$ of $\mathrm{NaCl}$ solution for the ages studied (28, 90, 180 et 365 days). From the analysis of the results obtained, it is possible to see a diminution of sorptivity values of HPC and HPFRC with time advancement, regardless of conservation environments. The introduction of PPF6 and PPF 12 into HPC resulted in the diminution of the sorptivity values. This diminution ranged between $2 \%$ and $5 \%$ for HPC with PPF6, while this value ranged between $7 \%$ to $14 \%$ for HPC with PPF 12 at 28 and 365 days, respectively as compared with unreinforced HPC. Also, it was observed that the fiber length had no noticeable effect on the sorptivity values. The improvement in the sorptivity values signify that polypropylene fibers successfully reduced the available capillary pores present in concretes [38]. Moreover, the substitution of cement by $6 \%$ of fine pozzolan (surface area $=9400 \mathrm{~cm}^{2} / \mathrm{g}$ ) further contribute in reducing the water flow through pores network by creating a denser material through the formations of C-S-H gel as well as by reducing the number of connected pores [39]. On the other hand, the combination of both polypropylene fibers at a total volume content of $0.25 \%$ resulted in a higher sorptivity in comparison with mono-fiber reinforced concretes and unreinforced HPC. This sorptivity value growth ranged between $15 \%$ and $10 \%$ at 28 and 365 days of curing in the two environments of conservation.

Test results indicate a negligeable effect of $\mathrm{NaCl}$ solution on the sorptivity of unreinforced and reinforced HPC with and without fibers used in this study. This confirms the good behavior of polypropylene fibers when subjected to aggressive environment. Indeed, the difference of sorptivity values for all concretes stored in tap water and

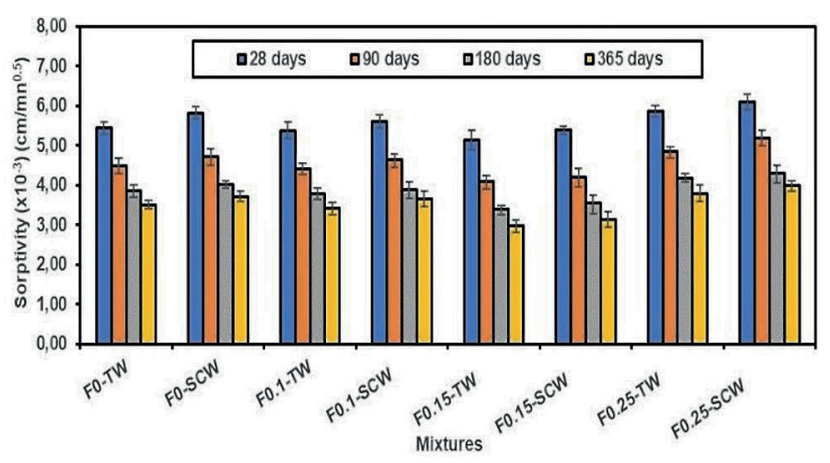

Fig. 10 Sorptivity values of all concretes stored in two conservation environments at 28, 90, 180 and 365 days 
sodium chloride environment varied between $8 \%$ to $11 \%$ for HPC while this value ranged between $14 \%$ to $13 \%$ for HPFRC at 28 and 365 days, respectively.

\subsection{Rapid Chloride Permeability Test (RCPT)}

A porous concrete is not necessarily a permeable concrete. Permeability depends more on the connectivity of the pores than on the total porosity of the material [40]. The resistance to chloride penetration ion results as a function of fibers inclusion as well as curing time and water conservation are illustrated in Fig. 11.

The inclusion of polypropylene fibers increased the permeability of HPC in both water conservation and testing age. However, both HPC and HPFRC recorded comparable permeability, particularly after 90 days of conservation. Based on the ASTM C1202 [28] classification given in Table 6, which gives an indication of the permeability of concretes as function of charge passed, the HPC and HPFRC mixes obtained a very low resistance to chloride ions permeability at long-term (180 and 365 days) regardless of conservation environments. For instance, the concretes without fibers obtained a charge passed from 1100 to $1200 \mathrm{C}$ and from 375 to $425 \mathrm{C}$ at 28 and 365 days respectively. While, concretes with fibers obtained a charge passed from 1200 to $1400 \mathrm{C}$ and 350 to $800 \mathrm{C}$.

The resistance to chloride penetration is mainly linked to the pore structures [41]. Hence, the addition of fine pozzolan (surface area $=9400 \mathrm{~cm}^{2} / \mathrm{g}$ ) favorably modifies the

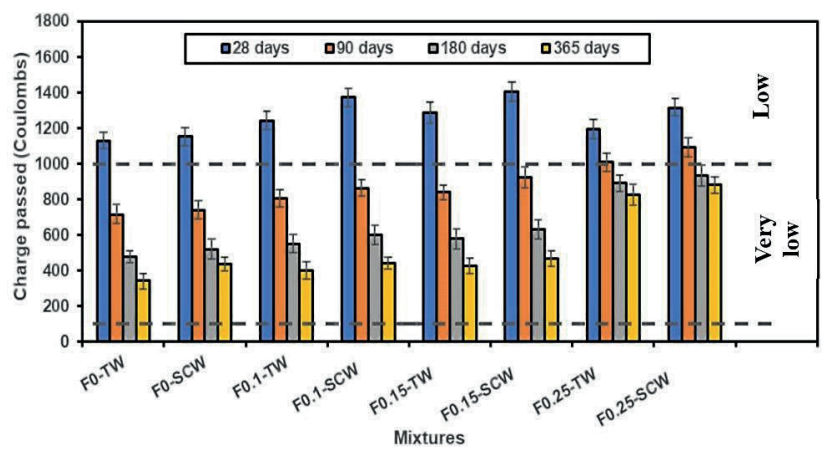

Fig. 11 Charge passed of all concretes stored in two conservation environments at 28,90, 180 and 365 days

Table 6 Chloride Ions penetration based on charge passed

\begin{tabular}{lc}
\hline Charge passed (coulomb) & Chloride ions penetration \\
\hline$>4000$ & High \\
$2000-4000$ & Moderate \\
$1000-2000$ & Low \\
$100-1000$ & Very low \\
$<100$ & Negligible \\
\hline
\end{tabular}

pores structures by the mean of filling effect and pozzolanic reaction which consequently enhances the resistance to chloride penetration. On the opposite, the polypropylene fibers negatively affect the pores system by adding more voids, as confirmed previously, in the study of Toutanji [42]. The author recorded a decrease in the permeability with the use of polypropylene fibers at $0.1 \%$, $0.3 \%$, and $0.5 \%$. However, the incorporation of silica fume reduced the adverse effect of fibers. In the same sense, Faraj et al. [43] found similar results. In this study, the maximum difference in the charge passed values for the HPC and HPFRC conserved in tap water and $\mathrm{NaCl}$ environment is $9 \%$ and $10 \%$ respectively, regardless of time curing. The difference in the charge passed values obtained confirms the polypropylene fibers resistance to corrosion and their long-term effect on the durability of concretes under chloride attack. Test results also show that polypropylene fiber length $(6$ and $12 \mathrm{~mm})$ slightly affected the permeability of HPC exposed to $\mathrm{NaCl}$ solution over time as these concretes obtained a similar electrical charge passed and classification to chloride ions permeability with time advancement.

\subsection{Apparent and intrinsic gas permeability}

The coefficient of apparent and intrinsic gas permeability of specimens containing fibers and immersed in tap water and chloride environment is given at 28,90, 180, and 365 days of conservation in Fig. 12 and Fig. 13. For both F0-TW and F0-SCW almost similar values are recorded. The coefficient was in the order of 0.63 to $0.32 \times 10^{-17} \mathrm{~m}^{2}$ for F0-TW and 0.72 to $0.36 \times 10^{-17} \mathrm{~m}^{2}$ for F0-SCW at 28 and 365 days respectively, which represent a reduction of $49 \%$ and $46 \%$ for both mixtures. The addition of natural pozzolan results in a denser microstructure and discontinuity of the existing pores [2].

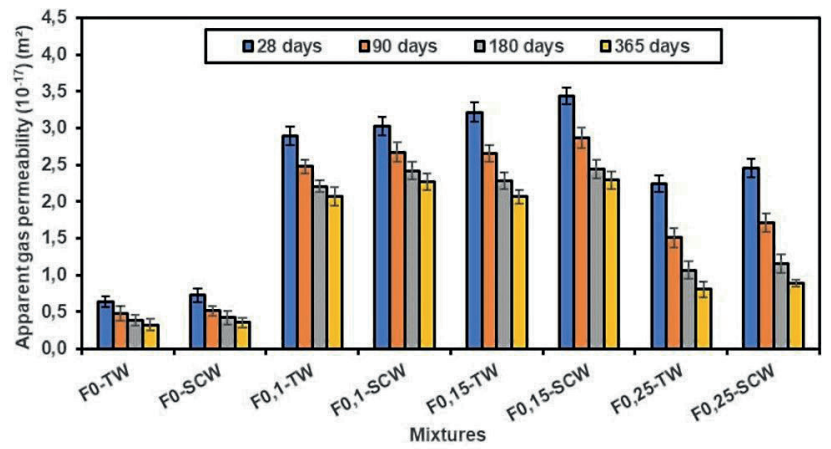

Fig. 12 Apparent gas permeability at an inlet of $0.2 \mathrm{MPa}$ of the different concretes stored in two conservation environments at various time $(28,90,180$ and 365 days $)$ 


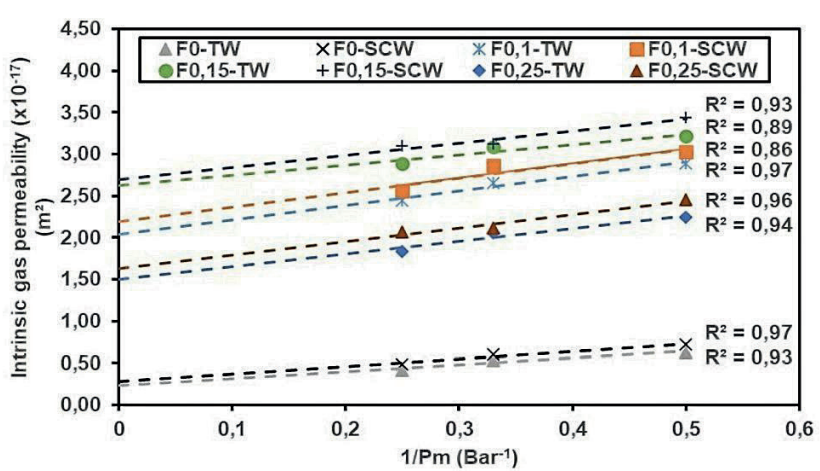

(a)

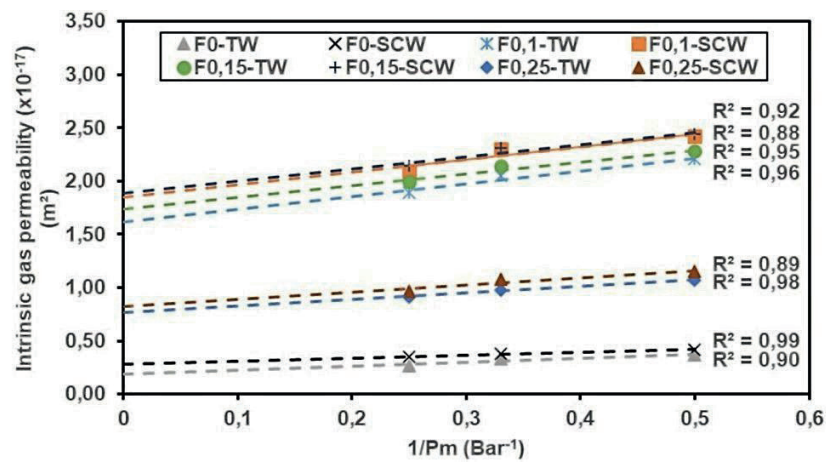

(c)

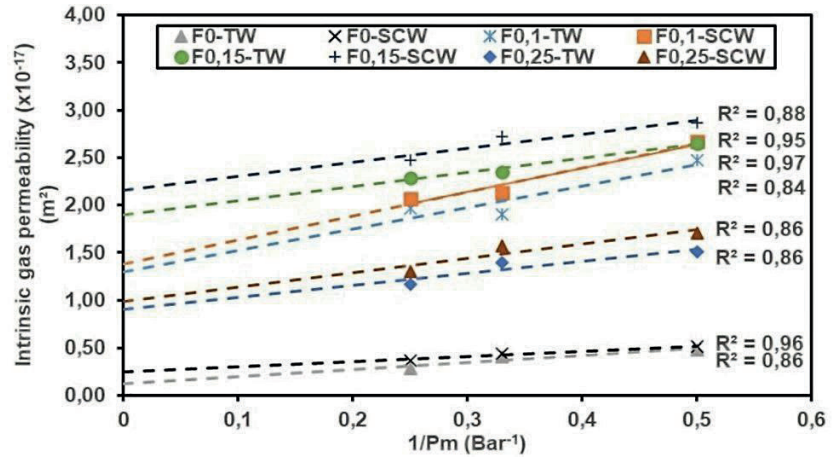

(b)

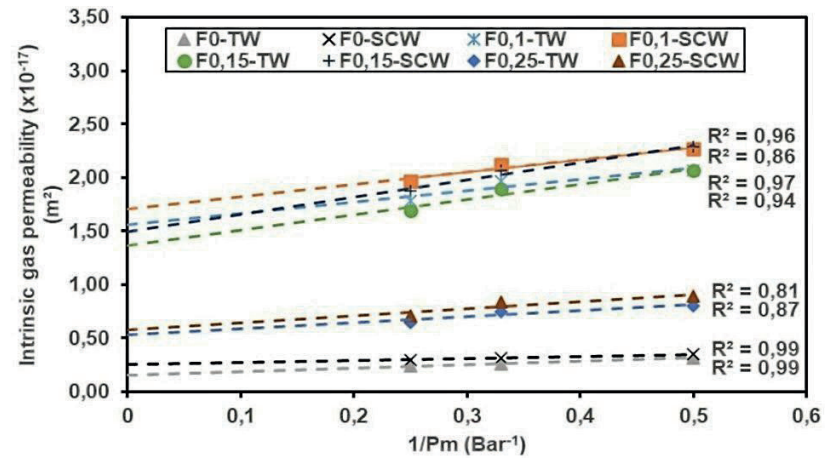

(d)

Fig. 13 Intrinsic gas permeability of all concretes in the two environments of conservation at (a) 28 days, (b) 90 days, (c) 180 days and (d) 365 days

The gas permeability clearly increases with the addition of $0.1 \%$ of PPF 6 and $0.15 \%$ of PPF 12 as well as with the combination of both of them. The coefficient of apparent gas permeability varied between 0.80 and $3.4 \times 10^{-17} \mathrm{~m}^{2}$ regardless of water conservation and testing age. The increase in the gas permeability coefficient of polypropylene fibers reinforced concrete may be explained by the aptitude of fibers to act as links between pores, which in turn constitutes interconnections and preferential paths for the movement of the gas flow inside the porous system of concrete [36]. On the other hand, the combination of concretes with polypropylene fibers of $6 \mathrm{~mm}$ and $12 \mathrm{~mm}$ of length result in the least gas permeability value, as compared to concretes with mono fibers. This value ranged between 2.2 to $0.8 \times 10^{-17} \mathrm{~m}^{2}$ for tap water and from 2.5 to $0.9 \times 10^{-17} \mathrm{~m}^{2}$ for chloride water. The combination of fibers seems to diminish the adverse effect of individual fibers inclusion as reported in the study of Dawood and Ramli [44].

As it can be seen in Fig. 12, the permeability loss of each HPFRC exposed in the two-water conservation ranged between $5 \%$ to $12 \%$, depending on fiber introduction and testing age. On the other hand, the permeability loss of each HPC ranged between $14 \%$ to $9 \%$. Test results proves that the $\mathrm{NaCl}$ solution slightly affect the apparent gas permeability of HPC reinforced by different polypropylene fibers length (6 and $12 \mathrm{~mm}$ ). Hence, the HPC reinforced with polypropylene fibers form an impermeable medium that limits the passage of gas as well as chloride ions penetration from aggressive solution through the pores system.

Fig. 13 shows the intrinsic gas permeability obtained by plotting the apparent gas permeability of concretes against the inverse of the mean pressure $\left(1 / P_{m}\right)$ at various cures and water conservation. Test results show a similar trend as observed with the apparent oxygen permeability shown in Fig. 12.

The coefficient of intrinsic permeability obtained by the Klinkenberg correlation [31] was found to be linear for all specimens with time advancement regardless of conservation environments. Indeed, it can be seen a satisfying correlation factor $\mathrm{R}^{2}$ of HPC and HPFRC ranged between 0.81 to 0.99 for a conservation between 28 to 365 days respectively. Hence, the gas measurements can be considered as a laminar flow of a compressible fluid through a porous system [45].

\subsection{Visual investigation}

Fig. 14 shows the visual inspection of polypropylene Fiber Reinforced Concrete under the effect of tap water and chloride attack after 365 days of immersion. These concretes retained their cubic shapes and dimensions. Indeed, 


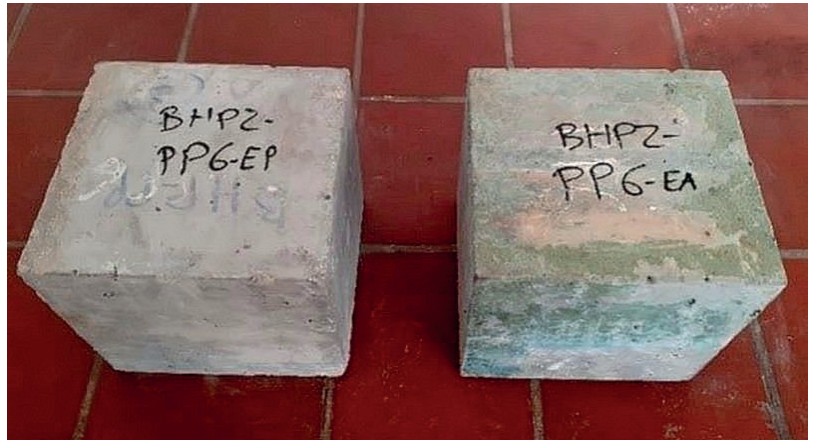

Fig. 14 Visual aspect of concretes reinforced with polypropylene fibers $(0.1 \%)$ after 365 days conservation in tap water (left) and $10 \%$ concentration of sodium chloride (right)

no signs of deterioration such as the appearance of cracks, spalling and excessive expansion were observed on the surfaces of concretes. However, green stains and a thin brown layer are observed on the sides of concrete in contact with the sodium chloride solution by comparison with the same concrete in contact with the tap water, which maintained its initial color and appearance.

Based on the visual inspection of the concretes and the observations performed, there is a good relationship between the results of the evaluated parameters (strength and permeability) and the visual aspect of the concretes reinforced with polypropylene fibers. The strength and permeability as well as the visual damage of the concrete immersed in the sodium chloride solution were not severely affected after 365 days. Hence, polypropylene fibers were not influenced by the aggressive solution and had not contributed to the degradation of concrete performance.

\section{Conclusions}

In this paper, the permeability of High-Performance Concrete incorporating local pozzolan and polypropylene fibers immersed in sodium chloride environment was investigated. The following conclusions are drawn based on the results and discussion:

- The difference in strengths of HPC and HPFRC stored in tap water and $\mathrm{NaCl}$ solution is negligeable (less

\section{References}

[1] Gupta, H., Bansal, P. P., Sharma, R. "Development of high-performance hybrid fiber reinforced concrete using different fine aggregates", Advances in concrete construction, 11(1), pp. 19-32, 2021. https://doi.org/10.12989/acc.2021.11.1.019

[2] Konečný, P., Ghosh, P., Hrabová, K., Lehner, P., Teplý, B. "Effective methodology of sustainability assessment of concrete mixtures", Materials and Structures, 53(4), Article number: 98, 2020. https://doi.org/10.1617/s11527-020-01535-3 than $4 \%$ and $11 \%$ for compressive and splitting-tensile strength, respectively). This implies, that polypropylene fiber does not participate in the degradation of concretes immersed in chloride environment.

- Polypropylene fibers show a long-term durability in $\mathrm{NaCl}$ solution, as the difference in sorptivity values of HPFRC ranged between $14 \%$ to $13 \%$ in comparison with those of HPC ranged between $8 \%$ to $11 \%$ at 28 and 365 days respectively.

- The use of polypropylene fibers increased the permeability of HPC immersed in the two environments. The charge passed through HPC and HPFRC was almost comparable, particularly after 90 days of testing, with a low resistance to chloride ions permeability. Similarly, the apparent gas permeability of these concretes ranged between $14 \%$ to $9 \%$ for HPC and $5 \%$ to $12 \%$ for HPFRC, regardless of environment conservation and testing age. The minimum difference obtained confirm the polypropylene fibers resistance to corrosion and their long-term effect on the durability of concretes under chloride attack.

- Green stains and a thin brown layer are visually observed on the sides of HPCs exposed for one year at $10 \%$ concentration of sodium chloride solution by comparison with the same concrete in contact with the tap water. However, no sign of cracking, spalling, or expansion were noticed.

Finally, High-Performance Concrete reinforced with Polypropylene fibers can be successfully produced in aggressive chloride environments such as those encountered in seawater and deicing salt. These concretes can maintain good strength and durability. The low permeability of HPFRC limits the penetration of harmful substances and can provide appropriate protection to steel reinforcement bars against corrosion. Consequently, the lifetime of reinforced concrete structures is extended. Based on the results obtained in this study, we recommend the use of hybrid fiber-reinforced concrete (F0-0.25\%) as a low permeable material in a severe chloride environment.

[3] Ghalehnovi, M., Roshan, N., Taghizadeh, A., Shamsabadi, E. A., Hadigheh, S. A., Brito, J. "Production of Environmentally Friendly Concrete Incorporating Bauxite Residue and Silica Fume", Journal of Materials in Civil Engineering, 34(2), Article number: 04021423, 2022.

https://doi.org/10.1061/(ASCE)MT.1943-5533.0004060 
[4] Chindaprasirt, P., Kroehong, W., Damrongwiriyanupap, N., Suriyo, W., Jaturapitakkul, C. "Mechanical properties, chloride resistance and microstructure of Portland fly ash cement concrete containing high volume bagasse ash", Journal of Building Engineering, 31, Article number: 101415, 2020.

https://doi.org/10.1016/j.jobe.2020.101415

[5] Sharma, S. K., Ransinchung, G. D., Kumar, P. "Investigating the use of Wollastonite micro fiber in yielding SCC", Advances in Concrete Construction, 6(2), pp. 123-143, 2018.

https://doi.org/10.12989/acc.2018.6.2.123

[6] Talah, A., Kharchi., F., Chaid., R, Merida, A. "The influence of natural pozzolan content on Durability of high-performance concrete", presented at Sixth International Symposium on Advances in Science and Technology, Kuala Lumpur, Malaysia, March, 21-25, 2012.

[7] Senhadji, Y., Escadeillas, G., Khelafi, H., Mouli, M., Benosman, A. S. "Evaluation of natural pozzolan for use as supplementary cementitious material", European Journal of Environmental and Civil Engineering, 16, pp. 77-96, 2012.

https://doi.org/10.1080/19648189.2012.667692

[8] Fodil, D., Mohamed, M. "Compressive strength and corrosion evaluation of concretes containing pozzolana and perlite immersed in aggressive environments", Construction and Building Materials, 179, pp. 25-34, 2018

https://doi.org/10.1016/j.conbuildmat.2018.05.190

[9] Chihaoui, R., Khelafi, H., Mouli, M. "The effect of natural pozzolan on sulfate resisting cement exposed to sodium sulfate attack for attaining sustainable building material", Key Engineering Materials, 650, pp. 122-130, 2015.

https://doi.org/10.4028/www.scientific.net/KEM.650.122

[10] Kumar, C. N. S., Krishna, P. V. V. S. S. R., Kumar, D. R. "Effect of fiber and aggregate size on mode-I fracture parameters of high strength concrete", Advances in Concrete Construction, 5(6), pp. 613-624, 2017.

https://doi.org/10.12989/acc.2017.5.6.613

[11] Lin, J.-X., Song, Y., Xie, Z.-H., Guo, Y.-C., Yuan, B., Zeng, J.-J., Wei, X. "Static and dynamic mechanical behavior of engineered cementitious composites with PP and PVA fibers", Journal of Building Engineering, 29, Article number: 101097, 2020. https://doi.org/10.1016/j.jobe.2019.101097

[12] Islam, G. M. S., Gupta, S. D. "Evaluating plastic shrinkage and permeability of polypropylene fiber reinforced concrete", International Journal of Sustainable Built Environment, 5(2), pp. 345-354, 2016.

https://doi.org/10.1016/j.ijsbe.2016.05.007

[13] Turk, K., Kina, C., Oztekin, E. "Effect of macro and micro fiber volume on the flexural performance of hybrid fiber reinforced SCC", Advances in Concrete Construction, 10(3), pp. 257-69, 2020.

https://doi.org/10.12989/acc.2020.10.3.257

[14] Mahmod, M., Hanoon, A. N., Abed, H. J. "Flexural behavior of self-compacting concrete beams strengthened with steel fiber reinforcement", Journal of Building Engineering, 16, pp. 228-237, 2018.

https://doi.org/10.1016/j.jobe.2018.01.006
[15] Mohammadhosseini, H., Tahir, M. M., Alaskar, A., Alabduljabbar, H., Alyousef, R. "Enhancement of strength and transport properties of a novel preplaced aggregate fiber reinforced concrete by adding waste polypropylene carpet fibers", Journal of Building Engineering, 27, Article number: 101003, 2020.

https://doi.org/10.1016/j.jobe.2019.101003

[16] Sadrinejad, I., Madandoust, R., Ranjbar, M. M. "The mechanical and durability properties of concrete containing hybrid synthetic fibers", Construction and Building Materials, 178, pp. 72-82, 2018. https://doi.org/10.1016/j.conbuildmat.2018.05.145

[17] Qu, F., Li, W., Dong, W., Tam, V. W. Y., Yu, T. "Durability performance deterioration of concrete under marine environment from material to structure: A critical review", Journal of Building Engineering, 35, Article number: 102074. 2020. https://doi.org/10.1016/j.jobe.2020.102074

[18] Frazão, C. M. V., Barros, J. A. O., Bogas, J. A. "Durability of recycled steel fiber reinforced concrete in chloride environment", Fibers, 7(12), Article number: 111, 2019.

https://doi.org/10.3390/fib7120111

[19] Peterson, O. "Chemical effects on cement mortar of calcium magnesium acetate as a deicing salt", Cement and Concrete Research, 25(3), pp. 617-626, 1995.

https://doi.org/10.1016/0008-8846(95)00050-M

[20] Darwin, D., Browning, J., Gong, L., Hughes, S. R. "Effects of Deicers on Concrete Deterioration", ACI Materials Journal, 105 (6), pp. 622-627, 2008.

[21] Mehta, P. "Durability of concrete exposed to marine environment -a fresh look", presented at International Conference on Performance of Concrete in Marine Environment, St. Andrews By-the-Sea, Canada, Aug. 21-26, 1988.

[22] Büyüköztürk, O., Lau, D. "High performance concrete: fundamentals and application", presented at The International Conference on Developments and Application of Concrete Technology, Istanbul, Turkey, Nov. 28-30, 2007.

[23] Banthia, N., Bhargava, A. "Permeability of stressed concrete and role of fiber reinforcement", ACI Materials Journal, 104(1), pp. 70-76, 2007. https://doi.org/10.14359/18497

[24] ASTM "C39/C39M-04 Standard Test Method for Compressive Strength of Cylindrical Concrete Specimens", ASTM International, West Conshohocken, PA, USA, 2004. https://doi.org/10.1520/C0039_C0039M-04

[25] ASTM "C496/C496M-04 Standard Test Method for Splitting Tensile Strength of Cylindrical Concrete Specimens", ASTM International, West Conshohocken, PA, USA, 2004. https://doi.org/10.1520/C0496_C0496M-04

[26] Wittmann, F. H., Zhao, T. "Knowledge of microstructure of concrete for the design of durable reinforced concrete structures", presented at Second International Conference on Microstructuralrelated Durability of Cementitious Composites, Amsterdam, The Netherlands, April, 11-13, 2012.

[27] ASTM "C1585-20 Standard Test Method for or Measurement of Rate of Absorption of Water by Hydraulic-Cement Concretes", ASTM International, West Conshohocken, PA, USA, 2020. https://doi.org/10.1520/C1585-20 
[28] ASTM "C1202-19 Standard Test Method for Electrical Indication of Concrete's Ability to Resist Chloride Ion Penetration", ASTM International, West Conshohocken, PA, USA, 2019. https://doi.org/10.1520/C1202-19

[29] Talah, A., Kharchi, F. "A modified test procedure to measure gas permeability of hollow cylinder concrete specimens", International Journal of Engineering and Technology, 5(1), pp. 91-94, 2013. https://doi.org/10.7763/IJET.2013.V5.518

[30] AFPC-AFREM Groupe de travail Durabilité des bétons "Recommended test methods for measuring the parameters associated to durability", In: Proceedings des Journées Techniques AFPC-AFREM: Durabilité des Bétons, Toulouse, France, Dec. 11-12, 1998. (in French)

[31] Klinkenberg, L. "The permeability of porous media to liquids and gases", In: Drilling and Production Practice, Washington, DC, USA, 1941, pp. 200-213.

[32] Kameche, Z. A., Ghomari, F., Choinska, M., Khelidj, A. "Assessment of liquid water and gas permeabilities of partially saturated ordinary concrete", Construction and Building Materials, 65, pp. 551-565, 2014.

https://doi.org/10.1016/j.conbuildmat.2014.04.137

[33] Rozière, E. R. "Study of durability by a performance-based approach", PhD thesis, Ecole Centrale de Nantes, 2007. (in French)

[34] Meddah, M. S., Bencheikh, M. "Properties of concrete reinforced with different kinds of industrial waste fibre materials", Construction and Building Materials, 23(10), pp. 3196-3205, 2009. https://doi.org/10.1016/j.conbuildmat.2009.06.017

[35] Tabatabaeian, M., Khaloo, A., Joshaghani, A., Hajibandeh, E. "Experimental investigation on effects of hybrid fibers on rheological, mechanical, and durability properties of high-strength SCC", Construction and Building Materials, 147, pp. 497-509, 2017. https://doi.org/10.1016/j.conbuildmat.2017.04.181

[36] Zhang, S., Zhao, B. "Influence of polypropylene fibre on the mechaical performance and durability of concrete materials", European Journal of Environmental and Civil Engineering, 16(10), pp. 1269-1277, 2012. https://doi.org/10.1080/19648189.2012.709681

[37] Song, P. S., Hwang, S., Sheu, B. C. "Strength properties of nylonand polypropylene-fiber-reinforced concretes", Cement and Concrete Research, 35(8), pp.1546-1550, 2005. https://doi.org/10.1016/j.cemconres.2004.06.033
[38] Ramezanianpour, A. A., Esmaeili, M., Ghahari, S. A., Najafi, M. H. "Laboratory study on the effect of polypropylene fiber on durability, and physical and mechanical characteristic of concrete for application in sleepers", Construction and Building Materials, 44, pp. 411-418, 2013.

https://doi.org/10.1016/j.conbuildmat.2013.02.076

[39] Sadrmomtazi, A., Tahmouresi, B., Amooie, M. "Permeability and mechanical properties of binary and ternary cementitious mixtures", Advances in Concrete Construction, 5(5), pp. 423-436, 2017.

https://doi.org/10.12989/acc.2017.5.5.423

[40] Miloud, B. "Permeability and porosity characteristics of steel fiber reinforced concrete", Asian Journal of Civil Engineering (Building and Housing), 6(4), pp. 317-330, 2005.

[41] Zhang, M., Li, H. "Pore structure and chloride permeability of concrete containing nano-particles for pavement", Construction and Building Materials, 25(2), pp. 608-616, 2011. https://doi.org/10.1016/j.conbuildmat.2010.07.032

[42] Toutanji, H. A. "Properties of polypropylene fiber reinforced silica fume expansive-cement concrete", Construction and Building Materials, 13(4), pp. 171-177, 1999.

https://doi.org/10.1016/S0950-0618(99)00027-6

[43] Faraj, R. H., Sherwani, A. F. H., Daraei, A. "Mechanical, fracture and durability properties of self-compacting high strength concrete containing recycled polypropylene plastic particles", Journal of Building Engineering, 25, Article number: 100808, 2019. https://doi.org/10.1016/j.jobe.2019.100808

[44] Dawood, E. T., Ramli, M. "Durability of high strength flowing concrete with hybrid fibres", Construction and Building Materials, 35, pp. 521-530, 2012. https://doi.org/10.1016/j.conbuildmat.2012.04.085

[45] Ltifi, M., Zafar, I. "Effect of total substitution of crushed limestone sand on concrete durability", European Journal of Environmental and Civil Engineering, 2019. https://doi.org/10.1080/19648189.2019.1649199 